\title{
Interviewing Dr Felipe Fregni: A Pathway to a Research Career
}

Juliana Bonilla-Velez, ${ }^{1}$ Whitney Stefanny Cordoba-Grueso. ${ }^{2}$

About the Author: Juliana Bonilla Velez is one of the founders of the IJMS and a pupil of the Principles and Practice of Clinical Research course. As a visionary physician, she has served in a number of roles within the Association of Scientific So cieties of Medical Students of Colombia (ASCEMCOL) and the International Federation of Medical Students Associations (IFMSA).

Whitney Cordoba Crueso is the Youth Category winner of the 2014 "Afro-Colombian of the Year Award" and the former Director of Public Relations and Communications of IJMS. As a you th-empowerment leader, she has served in a number of roles within the ASCEM COL and the IFMSA.
A talented Brazilian physician investigator, Felipe Fregni, is an Associate Professor of Physical Medicine a Rehabilitation and Neurology at Harvard Medical School, where he directs the Neuromodulation Laboratory at the Department of Physical Medicine at Rehabilitation at Spaulding Rehabilitation Hospital at Massachusetts General Hospital. He completed his medical studies, Neurology residency, and a Doctor of Philosophy (PhD) at the University of Sao Paulo and continued on to pursue postgraduate studies as well as a Master of Public Health (MPH) at Harvard Medical School. His philanthropic nature led him to design the Collaborative Learning in Clinical Research Program and the Principles and Practice of Clinical Research course with the Department of Continuing Education at Harvard Medical School to educate on basic and advanced training in clinical trials for physicians around the world. 'As part of this course, he has reached to physicians and students of graduate and postgraduate studies in the medical field in 30 countries to offer a 9-month collaborative distance-learning course on clinical research. For this interview, he was invited to share his experiences and insight as a physician-scientist from Brazil with medical students worldwide.

1. Can you share with us a glimpse of your life history? Can you describe how your research career started?

I completed my medical school studies and residency at the University of Sao Paulo, Brazil. In the last months of my residency, I initiated my doctoral studies. The first time that I traveled to the United States was in 2000, where I completed an initial observership in the Department of Neurology at the Beth Israel Deaconess Medical Center (BIDMC) at Harvard Medical School. Here, I met the the Principal Investigator of the Laboratory of Brain Non-invasive Stimulation. Then, I went back to Brazil to finish my residency and continue my PhD studies. By the end of my PhD, I came back to Boston and started my post-doctorate fellowship.

When I came initially, I didn't know if I wanted to stay or not. I was open to opportunities. In my opinion, research is very important for you as a clinician. I knew that there are many limitations in the treatments we offer to patients and in order to
Figure 1. Dr. Felipe Fregni.

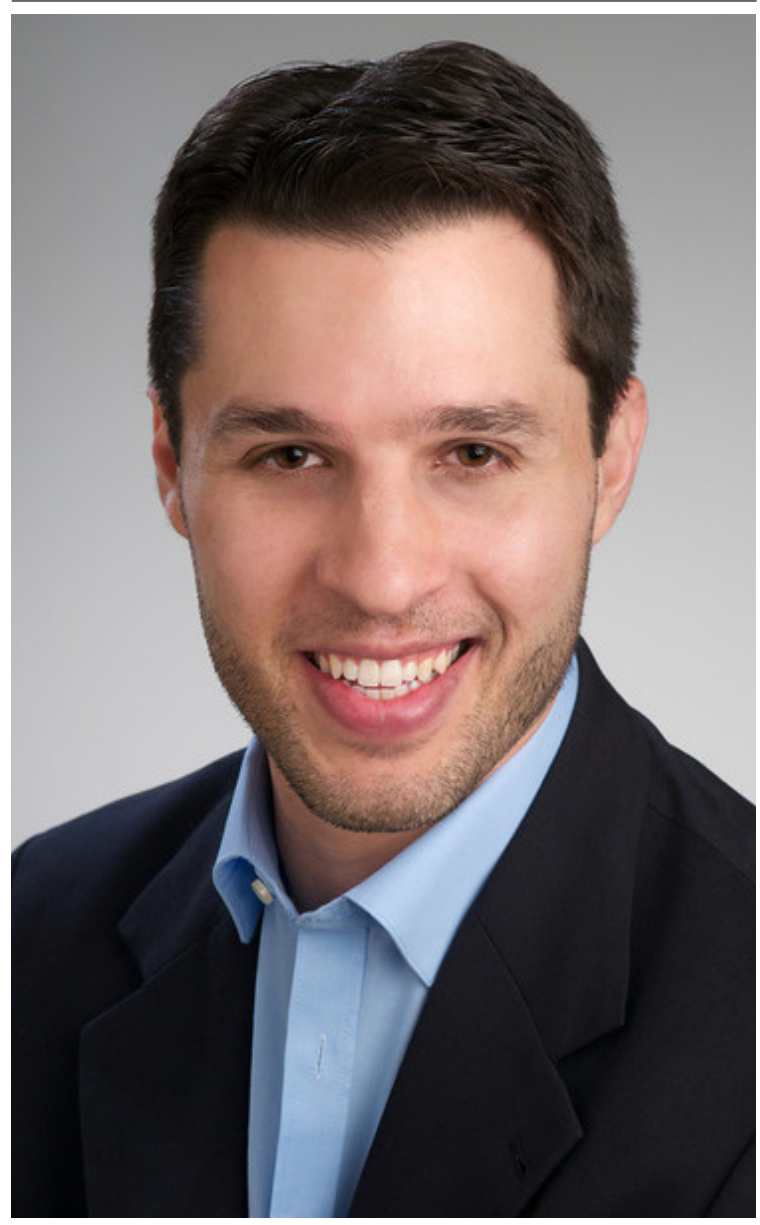

understand and to provide better care, you need to understand science and research well. And this is where my motivation was to come to the USA, a place where there was more focus on research integrated in clinical practice.

I then started the Scholars in Clinical Science Program followed by my MPH in the Clinical Effectiveness program at Harvard 
School of Public Health. At this point, my research was going well; I was getting published and I was offered a position initiaIly as Instructor and then as Assistant Professor of Neurology. Then, I was faced with the decision about whether I wanted to go back to more clinical work or stay more centered in research, and I chose to stay more dedicated to research and teaching. At this point, I was then recruited to Spaulding Rehabilitation Hospital where I have my own laboratory to continue my projects. And now I do most of my time in research

2. What were your thoughts and professional goals when you were a medical student?

As a medical student, what you are most focused on is figuring out in what you want to do your residency, and I was very open to specialties. One of my last rotations was neurology and I realized I really liked it. At this stage, I was focused on what my next step was going to be and that was residency so that was my main concern. I had thought about research and I knew I liked research. As a medical student, I was very critical of what I heard from my professors and if there was evidence to support our decisions, I was always questioning. I wouldn't imagine that when I graduated so many years ago that I would be here now and doing what I do now. I think you should be open to opportunities.

\section{Was there a defining moment when things changed?}

I think it was more a process. I had ideas in my head and there were issues in clinical practice that I wasn't happy and I didn't know how to resolve these issues- issues that kept me thinking. Then I thought that if I went through a research career and if I understood more and by doing that I would become even more passionate about Neurology. So I think it was a process, it took me since finishing medical school about 5-6 years to see that this was really what I wanted to do. I saw that this made sense in terms of what I believed in. I was never satisfied with current knowledge in medicine and the simplistic model for diseases and I wanted to do something different, to propose a change, and this would only be possible through research and producing new knowledge.

In my first year of medical school, before there was Internet, I came across a book in our medical school's library written by an editor of the New Scientist Journal, and I can never remember the actual name nor have I been able to find it, but it was called something like "The Magic Bullet" saying that there are so many limitations with drugs and that we don't fully understand what they're really about and then discusses the limitations of our knowledge. This helped me appreciate Medicine with different eyes. I think everything happens for a reason.

4.What was the process for you to arrive to your current line of research?

It was a couple of things. When I was doing my observership at BIDMC, I was with a group of students and one of them told me he was working in a laboratory that worked on brain stimulation and I thought that was very cool so I went to see it. For me it made a perfect match. It was a technique that could study brain plasticity, how the brain changes according to disease and behavioral stimulation and based on that it went across different conditions like stroke and Parkinson's disease, which gave me the opportunity to keep working on different conditions focused on learning more about how diseases change neuroplasticity and how these changes are locked. It was a great field for learning more in general as opposed to focusing on a very specific question, which was more what I wanted to do, something that would transcend, seeing a bigger picture

5. What is the contribution of your area of research to healthcare and answering the health problems that we face? What are the biggest challenges?

I think the main thing that we are showing is how the brain changes with diseases and that is important. Your brain changes because you have a lot of neurotransmitters released in response to disease or to a lesion, for example in stroke, but it also changes trying to adapt, trying to compensate for what has happened. So we're showing that, and showing that if you try to block or reverse some of these changes you can induce therapeutic effects. So this is a great contribution to clinical care. We're showing with quantitative methods that its not only disease but what we call maladaptive plasticity that has an effect on the brain. And in stroke we're showing that if you go not to the side of the lesion but to the contralateral side you can induce an improvement as well. We have also seen that if you have a lesion it can cause an excitability of the areas that cause chronic pain, and then the brain becomes more sensitive to stimulus in pain-related centers. So these are some of the contributions we are giving to medicine.

6. In your opinion, what is the future of research in Neurology?

It's a difficult question. I think research should be more balanced in terms of basic science and clinical so it can have more translation. For example, I gave a presentation on the PPCR course showing how we spend millions of dollars to develop interventions for acute stroke, from ten that showed great results in animals only one of them showed a significant result in humans in a small phase II trial and when it went to phase III trial it showed no changes. So, I think it is important to have more effort placed on translation. Another area that would help develop the field is finding better biomarkers for neurological diseases. There are no biomarkers for pain or stroke; there are some that can be used but they're not very reliable for Parkinson's disease and Alzheimer's disease, and you can see clinical outcomes - which is fine- but we don't have biomarkers as you have for other diseases like enzymes in myocardial injury.

In PMNR the great challenges are in terms of testing because most interventions are based on physical, occupational, and speech therapy more than pharmacological therapies, and these haven't been tested systematically. By studying them better it can help us understand which patients respond better to which treatments. So having more large open label studies would be interesting as well.

7. What has been the greatest accomplishment in your career? It's difficult to say, but for example for me some great accomplishments are having my own laboratory and mentoring stu- 
dents, as well as becoming faculty here. But one thing I think is a great accomplishment and I am very passionate about is the clinical research course because I think it is the only way you can have a system changed is though spreading knowledge. I think it would be a combination of these things. And also the research findings we've already discussed.

8. How have you contributed to the advancement of clinical research in developing countries?

This for me is very important. I've contributed in two ways. The mission is to improve clinical practice and to improve the level of clinical care because we can not just do all things ourselves so we need to try to help in areas where there's more need. There are different ways to help: one of them is the clinical research course, which was designed to be an international course with colleagues in Brazil and it has now reached many countries. Another one has been pursuing collaborations with some of the laboratories in developing countries. I know they face difficulties doing research at different levels, for example getting the equipment, so through our collaboration we've been able to do great projects together.

10. What advice would you give medical students who are interested in getting involved in research?

I think as medical students you need to be a bit lucky and be in a good school with good mentors and be more critical. What's most important is that you should choose your mentor and not only the mentor that is available to you, and that sometimes is hard to do. This is a match that serves both ways. I don't think in medical school the topic is as important - what to research in - but I think its more about who you choose to work with because then you learn what research is about; you learn the methods.

9. What advice do you have for medical students worldwide?

In the context of evidence-based medicine, l'd say be curious and critical of what you learn. Don't just do research because it improves your $\mathrm{CV}$; understanding research can lead you to do better clinical medicine and then look for someone who can really help you achieve that. And for future clinical investigators, you need to devote time and dedication to really learn well because it will take more than just 6 months of doing research. Working hard, you need 3 to 4 years to be able to then be independent in research.

\section{References}

1. Coronel E, Anez-Bustillos L, Fregni F. Training Future Scientists - Enhancing Research Capabilities in Developing Nations. Int J Med Students. 2013; $1(2): 64-5$. Acknowledgments
The authors of this Interview would like to thank Dr. Felipe Fregni for his valuable time and also for sharing his research experience with
the medical students worldwide.

Conflict of Interest Statement at Funding

The authors have no funding, financial relationships or conflicts of interest to disclose.

\section{Author Contributions}

Conception and design the work/idea, Collect data/obtaining results: JBV. Analysis and interpretation of data, Write the manuscript, Critical revision of the manuscript, Approval of the final version: JBV, WSCG.

Cite as: Bonilla-Velez J, Cordoba-Grueso WS. Interviewing Dr Felipe Fregni: A Pathway to a Research Career. Int J Med Students. 2014 Nov2015 Mar;3(1):67-9. 